\title{
HOCALI SOYKIRIMI İLE İLGILİ TÜRK KAMUOYUNUN GÖRÜŞLERİ ÜZERİNE BİR ARAŞTIRMA \\ A RESEARCH ON THE VIEWS OF THE TURKISH PUBLIC ABOUT THE HOCALI GENOCIDE
}

\author{
Esma ÖZDAŞLI ${ }^{1}$
}

1. Dr. Öğr. Üyesi, Burdur Mehmet Akif Ersoy Üniversitesi, İktisadi ve İdari Bilimler Fakültesi, Uluslararası İlișkiler Bölümü, eozdasli@mehmetakif.edu.tr, \begin{tabular}{l} 
https://orcid.org/0000-0003-2336-9719 \\
\hline
\end{tabular}

\begin{tabular}{|c|c|}
\hline Makale Türü & Article Type \\
\hline Araştırma Makalesi & Research Article \\
\hline Başvuru Tarihi & Application Date \\
\hline 21.02.2020 & 02.21 .2020 \\
\hline Yayına Kabul Tarihi & Admission Date \\
\hline 24.07.2020 & 07.24 .2020 \\
\hline
\end{tabular}

https://doi.org/10.30798/makuiibf.692569 $\ddot{0} \mathbf{z}$

25-26 Şubat 1992 tarihinde, Ermeni silahlı kuvvetleri ve Rus 366. motorize gücünün, 10 bin nüfuslu Hocalı kasabasına gerçekleştirdiği saldırıda; 83 çocuk, 106 kadın ve 70'den fazla yaşlı dahil olmak üzere toplam 613 kiși öldürülmüş, 487 kişi ise ağır yaralanmıştır. İnsanlık dışı işkence yöntemleriyle öldürülen bu insanların dışında çok sayıda kişi rehin alınmış ve bazı Hocalı sakinleri ise kaybolmuştur. İnsan Hakları İzleme Örgütü'nün "Dağlık Karabağ Savaşı'ndan bu yana gerçekleștirilen en kapsamlı "sivil" katliam olarak nitelendirdiği bu facianın faillerinin, hala hiçbir ceza almamaları uluslararası hukuka olan inancı zedeleyen önemli bir husustur. Uluslararası hukuk açısından en büyük insanlık suçu olarak kabul edilen "soykırım”'ı tanımlayan 1948 tarihli Birleşmiş Milletler Soykırımın Önlenmesi ve Cezalandırılması Sözleşmesi’nin her maddesine göre Hocalı'da yaşananlar bir "soykırım"dır. Ancak Batılı ülkeler bașta olmak üzere dünyanın görmezden geldiği bu olay, Türk Dünyası'nda hatta Türkiye'de dahi tam olarak bilinmemektedir. Bu çalıșma, Hocalı Soykırımı ile ilgili olarak araștırma örneklemi nispetinde Türk kamuoyunun algısının ne yönde olduğunun tespit edilebilmesi için yapılmıştır. Bu çerçevede, NVivo 12 Paket Programı yardımıyla yapılandırılmış görüşmeler neticesinde elde edilen metinler üzerinde İçerik Analizi (Temasal Analiz) yapılımış ve elde edilen frekans dağılımları ve kavram haritaları sayesinde yorumlara gidilmiştir.

Anahtar Kelimeler: Hocalı Soykırımı, Türkiye, Azerbaycan, Kamuoyu, Íçerik Analizi,

\section{Abstract}

On 25-26 February 1992, Armenian armed forces and the Russian 366th motorized force attacked Khojali which had a population of 10 thousand. 613 people were killed, including 83 children, 106 women and more than 70 elderly people, and 487 people were seriously injured. Moreover, many people were taken hostage and some of the Khojaly residents were lost. The perpetrators of this disaster, which Human Rights Watch described as the most comprehensive "civilian" massacre since the NagornoKarabakh War, are still an important issue that undermines the belief in international law. Khojaly massacre is a "genocide" according to every article of the 1948 United Nations Convention on Prevention and Punishment of Genocide which defines the genocide as the biggest crime against humanity in terms of international law. However, this event, which is ignored by international community, is also not commonly known in Turkic World and Turkey. This study is carried out to determine the direction of Turkish public opinion regarding the Khojaly Genocide. In this context, Content Analysis is conducted on the texts obtained as a result of the structured interviews with the help of NVivo 12 Package Program and comments are made thanks to the frequency distributions and concept maps obtained.

Keywords: Khojaly Genocide, Turkey, Azerbaijan, Public Opinion, Content Analysis, 


\section{EXTENDED SUMMARY}

\section{Research Problem}

This study is carried out to determine the perception of the Turkish public opinion regarding the Khojaly Genocide. In this framework, it aims to reveal the attitudes and thoughts of different community groups towards the Khojaly Genocide. To provide information to the Azerbaijan State for the process of forming public opinion regarding the Khojaly Genocide is also the objective of this study.

\section{Research Questions}

Within the scope of the research, the answers of the following questions were sought: 1. How would you define the events in Khojaly? 2. When was the first time you heard about the Khojaly Genocide? 3. Which events and experiences originated your awaress regarding the Khojaly genocide? 4. Do you believe that an international awereness has been raised adequately about the Khojaly Genocide? 5. Do you think that are there adequate lobbying by Turkey and Azerbaijan about Khojaly Genocide? 6. What should be done at the social and institutional level to raise awareness about the Khojaly Genocide? 7. Did you work to announce this incident internationally individually or as a group after you have been informed about the Khojaly Genocide?

\section{Methodology}

The research population is made up of social media users who follow the researcher at their social media accounts. With the Convenience Sampling method, a Structured Questionnaire was sent to the followers of different social sections of the researcher's own social media accounts. There were 198 people who accepted and answered the questionnaire. Structured Interview is used as data collection method in the research. As it is well known, the interview method is used in both quantitative and qualitative research. In the structured interview method, the previously prepared questions are asked to the participants and their answers are recorded. In accordance with the subject of the research, 7 questions that were prepared beforehand are directed to the people who accept the interview. The data obtained as a result of these interviews are primary data because people are directly asked about their views on the Khojaly Genocide.In this study, Content Analysis is used on the texts that are obtained as a result of the structured interviews with the help of NVivo 12 Package Program. Comments are made as a result of the frequency distributions and concept maps obtained.

\section{Results and Conclusions}

The main findings of the study are as follows: More than half of the participants (51\%) consider the event as genocide. As the average age of the interviewees is young, it is also among the findings that they learned the event especially after 2000. An overwhelming majority (approximately 89\%) of the interviewees think that not enough awareness is raised internationaly concerning the Khojaly Genocide. There is a strong impression that efforts of Turkey and Azerbaijan are not enough for international lobbying. In the framework of the study, it is found out that more needs to be done to raise awareness about the Genocide both in public opinion of Azerbaijan and Turkey as well as international public 
opinion. Particularly, it is emphasized by the participants that foreign media channels should be used more effectively and more broadcasts should be made in foreign languages. In this study, which was carried out in order to determine the perception of the Turkish public of the Khojaly Genocide, a determination has been made that a more effective policy should be followed to introduce the issue to the international community. Participants has made remarks that Turkey and Azerbaijan should follow a common policy to raise the awareness about the issue. They have also emphasized the importance of broadcasts in foreign languages and using social media channels more effectively. 


\section{GİRIŞ}

Kamuoyu kavramını genel anlamda, belirli bir dönem itibariyle, belirli sorunlarla ilgili toplum kesimlerinin sahip oldukları kanaat olarak tanımlamak mümkündür. Bu kanaatin ne kadar etkin olarak duyurulduğu da önemli bir diğer konudur (Kapani, 1983: 235). Kamuoyu oluşturma sürecinin, karar vericilerin karar yönünün tespit edilmesinde büyük önem arz ettiği, günümüzde kamuoyunun kendiliğinden oluşmadığını da belirtmek gerekmektedir. Kamuoyunun oluşturulmasında birinci önem arz eden nokta, bir konu veya sorun ile ilgili olarak o konu ya da sorun hakkında toplumun bilgilendirilmesi ya da haberdar edilmesi hususudur (Atabek, 2002: 235).

Bir olgu ya da olay ile ilgili olarak olay ya da olgudan etkilenen toplum kesimlerinin öncelikle bu olay ya da olguları sorun olarak değerlendirmesi ve bu konuda bir ortak görüşün oluşması söz konusudur. Oluşan bu görüş neticesinde ilgili toplum kesiminin belirgin bir tutuma sahip olması ve bu tutum doğrultusunda davranışlar geliştirmesi gerekmektedir. Bu olay ya da olgu ile ilgili kamuoyunun oluşmasında olumlu ya da olumsuz tepkiler gösterme eğilimi olarak tanımlanabilecek tutumlar büyük önem arz etmektedir. Olay ve olgu ile ilgili olarak toplum kesiminin elde ettiği bilgiler; sevgi, öfke, nefret vb. duyguları ve davranışsal tepkileri tutumlarının temel unsurlarıdır. Sahip olunan tutumlar toplum kesimindeki bireyler tarafından sözlü olarak ifade edilmeye başladığında o toplum kesiminin kanaatleri ortaya çıkmış olmaktadır (Yüksel, 2007: 574).

Sadece Azerbaycan tarihinin değil, insanlık tarihinin en kanlı hadiseleriniden biri olan Hocalı Soykırımı münferit bir olay değil, aksine Ermenilerin yaklaşık olarak 200 yıldır devam eden "denizden denize Büyük Ermenistan” hayallerinin en kanlı parçasıdır (Özdaşl1, 2015: 13). 25-26 Şubat 1992 tarihinde, Ermeni silahlı kuvvetleri ve Rus 366. motorize gücünün, 10 bin nüfuslu Hocalı kasabasına gerçekleştirdiği saldırıda; 83 çocuk, 106 kadın ve 70'den fazla yaşlı dahil olmak üzere toplam 613 kişi öldürülmüss, 487 kişi ise ağır yaralanmıştır. İnsanlık dışı işkence yöntemleriyle öldürülen bu insanların dışında 1275 kişi rehin alınmış, akibeti hala bilinmeyen 150'ye yakın kişi de kaybolmuştur. (Bagırov, 2017). Katliam sırasında 7 ailenin bütün fertleri öldürülmüş, 27 ailenin ise sadece bir ferdi ayakta kalabilmiş, 230 ailede anne veya baba öldürülmüştür. Katliamdan kaçmaya çalışan 200 kişi Gargar çayını geçmiş, soğuğun etkisi ile ayakları donmuştur. Yapılan tüm müdahalelere rağmen bu kişilerin ayakları kesilmiştir (Asker, 2017). Bunlar resmi rakamlardır. Tanıkların, gazetecilerin ve hatta bazı Ermenilerin verdikleri bilgilere göre katliam günü 1300 'den fazla insan hayatını kaybetmiştir (Asker, 2017).

Uluslararası hukuk açısından en büyük insanlık suçu olarak kabul edilen "soykırım"1 tanımlayan 1948 tarihli Birleşmiş Milletler Soykırımın Önlenmesi ve Cezalandırılması Sözleşmesi’nin her maddesine göre Hocalı'da yaşananlar bir "soykırım"dır. Ancak Batılı ülkeler başta olmak üzere dünyanın görmezden geldiği bu olay, Türk Dünyası'nda hatta Türkiye'de dahi tam olarak bilinmemektedir. Bu çalışma, Hocalı Soykırımı ile ilgili olarak araştırma örneklemi nispetinde Türk kamuoyunun algısının ne yönde olduğunun tespit edilebilmesi için yapılmıştır. 


\section{HOCALI SOYKIRIMI: TARIHSEL ARKAPLAN VE TEMEL NEDENLER}

Hocalı'nın işgali, daha önce de ifade edildiği üzere münferit bir olay değil, Ermenilerin 19. yüzyılın ortalarından itibaren Rusya'nın desteğiyle Azerbaycan topraklarına yönelik sürdürdüğü mütecaviz stratejilerinin bir devamıdır. Bu bakımdan, Hocalı'yı anlayabilmek için öncelikle Hocalı'nın da bir parçası olduğu Dağlık (Yukarı) Karabağ neresidir? Ruslar açısından önemi nedir? Ne şekilde işgal edilmiş̧ir? ve Azerbaycan'ın bölünmüşlüğü sorunu nasıl ortaya çıkmıştır? gibi konuların bilinmesi gerekmektedir.

Karabağ, Azerbaycan'ın Kür ve Aras 1rmakları ile günümüzde Ermenistan topraklarında bulunan Gökçe (Sevan) Gölü arasındaki dağlık bölge ile bu bölgeye bağlı ovalardan oluşmaktadır. Dağlık Karabağ yüzölçümü 18000 km² olan Karabağ'ın 4392 km²'lik kısmını oluşturmaktadır (Aslanlı, 2001: 393- 384). Azerbaycan'ın bölünmüşlüğü ve dolayısıyla Karabağ sorununun temelini, Rusya ile İran (Kaçar) arasında 18. yüzyılın başlarından itibaren yaşanmaya başlanan Kafkasya hakimiyet mücadelesi oluşturmaktadır. 1803-1813 arasında yapılan Rus-İran savaşları neticesinde Karabağ'a bağlı Gülistan köyünde imzalanan Gülistan Antlaşması ile Karabağ, Gence, Şeki, Bakü, Derbend, Kuba ve Taliş hanlıkları Rusya, Güney Azerbaycan hanlıkları ise İran hâkimiyetine bırakılmışıtır (Buniyatov, 1991: 320). Bu anlaşma, Türk Kafkası'nın büyük bir kısmının Rusya tarafından işgalinin resmi belgesidir ( Mehmetov, 2009: 484). 1826'da başlayan ve İran'ın yenilgisiyle sonuçlanan ikinci RusKaçar savaşından sonra 18 Şubat 1828'de imzalanan Türkmençay Anlaşması ile Azerbaycan'ın günümüze kadar gelen bölünmüşlüğü sorunu ortaya çıkmış, Gülistan Anlaşması'na ek olarak Erivan (İrivan) ve Nahçivan Hanlıkları da Rusya'ya verilmiştir (Mehmetov, 2009: 487). Söz konusu anlaşmalara göre Rusya tarafından kalan Kuzey Azerbaycan topraklarının bir kısmı Ermenilere verilmiş, (Dilican, Gökçe Gölü, Zengezur-Katar mıntıkası) 114 bin km² ülke toprağı Sovyet yönetimince ise 86 bin $\mathrm{km}^{2}$ ye düşürülmüştür. Bunun yanı sıra Ermenilerin zorlaması ile Azerbaycan'ın doğal sınırları içinde yer alan Nahçivan'a muhtar cumhuriyet, Dağlık Karabağ’a ise muhtar vilayet statüsü verilerek adım adım bu bölgelerin Azerbaycan ile bağı koparılmaya çalışılmıştır. SSCB'nin yıkılma sürecine girmesi ile birlikte Ermeniler Dağlık Karabăg'ın muhtar statüsünden yararlanarak bölgeyi kademeli olarak ele geçirmiştir (Alkan,2006: 138). Ermenilerin, Rusları Kafkasya hakimiyetine götürecek ne denli isabetli bir araç oldukları 1827'de Revan Ruslar tarafından ele geçirildiğinde Rus General Paskeviç’in Çar'a gönderdiği raporda net olarak görülmektedir: “...Bu sirada İrevan vilayetinde 10 bini Müslüman-Türk, 3 bini Ermeni olmak üzere 13 bin insan yaşıyordu. Bunlardan Ermeniler kalenin kuzey kapısını gizlice açtılar ve 1 Ekim'de Rusların şehre girmesine yardım ettiler." (Attar, 2013: 52)

Rusya'nın Kafkasya'ya yönelmesi ile tüm bölge halkları için uzun yıllar sürecek zorlu bir nüfus hareketliliği başlamıştır. 1828 yılında Türkmençay Anlaşması'nın 15. maddesine göre; Kaçar yönetimi altında yaşayan (büyük ölçüde günümüzdeki İran toprakları) 50.000, 1829 Osmanl1-Rus Edirne Anlaşması uyarınca ise Osmanlı topraklarında yaşayan 84.000 Ermeni'nin Karabağ başta olmak üzere Azerbaycan topraklarına göç ettirilmesine karar verilmiştir. Gerek zorunlu gerekse gönüllü olarak 20. 
yy.'nin başlarına kadar devam bu nüfus hareketleri neticesinde yaklaşık olarak 1 milyon 300 bin Ermeni Anadolu'dan ve İran'dan Kafkasya'ya göç etmiştir (Yeşilot, 2008: 192). Dolayısıyla, günümüzde tarihsel toprak iddialarında bulunarak Dağlık Karabağ'ın kendilerine ait olduğunu iddia eden Ermenilerin büyük bir kısmının bölgeye gelişi 19. yüzyılın ortalarına tekabül etmektedir. Sonuç olarak, Hocalı gibi bir "soykırımın" da yaşandığı Karabağ sorunun temeli, Rusların teşvikiyle Ermenilerin Azerbaycan topraklarını işgali ile başlamıştır.

Azerbaycan topraklarını ele geçiren Rusya, uzun yıllar sürdürdüğü Ermeni göç ve iskan politikası ile Türk Kafkasyası ile Anadolu ve İran'ın kesiştiği bölgede tampon bir Ermeni eyaleti oluşturularak, bölge denetimini elinde tutmayı hedeflenmiştir (Mehmetov, 2009: 487). Çarlık Rusya'nın ve SSCB'nin Kafkasya ve devamında Türkistan'a nüfuz etme politikasının temelini, Anadolu Türkleri ile Türkistan arasındaki bağlantıyı koparma planı oluşturmaktadır. Dolayısıyla Karabağ'ın işgali, Anadolu ile Türkistan arasındaki bu organik bağı ortadan kaldırarak, Aleksandr Dugin'in ifadesi ile Türkiye'yi kıta içi mekanlardan yani Türk dünyasından koparan bir işleve sahip olacaktır (Dugin, 2005: 78). Karabăg'ın Ermenilerce işgal edilmesi ile Nahçivan ile Azerbaycan arasına Ermeniler sokulmuş, böylece Azerbaycan'ın önemli bir bölgesi ile bağlantısı kesilmiş, dolayısıyla Ermenistan Türkiye ile Türk Dünyası arasına adeta bir hançer gibi saplanmıştır (Özdaşlı ve Kodaman, 2016: 77). Ermenistan, sadece Türkiye ve Azerbaycan'dan değil Gürcistan'ın Cehavati bölgesinden de asılsız toprak taleplerinde bulunarak tüm bölge için bir huzursuzluk kaynağı haline gelmiştir. Birçok yazarın üzerinde hem fikir olduğu üzere, dünyada büyük güçler Rusya ve ABD'nin aynı anda desteklediği tek ülke olması, bu nedenle de Dağlık Karabağ işgalini BM dahil bir çok uluslararası örgütün aldığı kararlara rağmen sürdürmesini kolaylaştırmaktadır.

\subsection{Ermeniler Hocalı'yı Neden Hedef Aldı?}

Hocalı'nın Ermenilerce işgal edilmesinin nedenleri arasında, Dağlık Karabağ'ın tek hava limanına sahip olmasının yanı sıra bulunduğu konum itibariyle önemli demiryolu ve karayolu bağlantılarının üzerinde olması ve Dağlık Karabağ'ın merkezi Hankendi’ye (Ermeniler işgalden sonra buraya Stapanakert adını vermişlerdir) 11 km mesafede olması sayılabilir. Dağlık Karabağ'ın merkezi olan Handikendi'nin elektrik hattı, Bakü-Handikendi demiryolu hattı ve Bakü-Şuşa karayolu da Hocalı'dan geçmektedir (Asker, 2017). Bununla birlikte Ermeniler, Hocalı'da bir soykırım gerçekleştirerek, ileride yapacakları saldırılarılara yönelik Azerbaycan Türkleri üzerinde psikolojik bir baskı oluşturmayı amaçlamış ve bölgenin asıl sahiplerinin yani Türklerin bu korku ile bölgeyi terk etmelerini sağlamaya çalışmışlardır. Bu yüzden de Hocalı'da hamile kadınların karınlarının deşilmesi, çocukların derilerinin yüzülmesi gibi en insanlık dışı uygulamalara imza atmışlardır. Bu açıdan, 199194 yılları arasında Karabağ'da Ermeni silahlı kuvvetlerine komuta eden Ermenistan'ın eski Cumhurbaşkanı Serj Sarkisyan'ın “Hocalı’ya kadar Azerbaycanlılar bizim sivilleri öldürmeyeceğimizi 
düşündü. Fakat Hocalı'da biz bunu yıktık" ifadeleri Ermenilerin bu stratejilerinin anlaşılması açısından önemlidir.

Aslında, Ermeniler Hocalı'ya gerçekleştirecekleri saldırının hazırlıklarını uzun süre yapmış, katliam bir anlamda geliyorum demiştir. Öncelikle, Asker'in de ifade ettiğgi gibi, Azerbaycan yetkilileri Hocalı'yı savunan görevlilerin tüm ikazlarına rağmen bu denli önemli bir mıntıkanın savunulmasına gereken hassasiyeti gösterememişlerdir. Ermeniler, kasabayı yavaş yavaş ve aslında pek de gizli olmayan bir yöntemle kontrol altına almışlardır. Son bir yıldır abluka altında tutulduğu için tek ulaşımın havadan yapıldığı Hocalı'ya son helikopter de 13 Şubat 1992'de Hocalı'ya yemek, ilaç ve yakıt getirmiştir. Ermenilerin elektriklerini de kestiği bölgenin dünya ile irtibatı kesilmiş ve Hocalı bir anlamda Ermenilerce katliama hazırlanmıştır. Hocalı'nın askeri anlamda savunma durumuna baktığımızda; sadece 200-250 otamatik silah, 1 adet top, 2 "Alazan" roketatar ve 1 zırhlı araçla donatılmış 160 kişilik bir savunma birliği olduğu görülmektedir (Asker, 2017). Buna karşın Moskova tarafından bizzat silahlandırılan Ermeni güçlerine bölgede konuşlu 366. Motorize Rus tugayının da katılması ile Ermeniler askeri anlamda üstünlüğ̈ ele geçirmişlerdir.

\section{ARAȘTIRMANIN METODOLOJISİ}

\subsection{Dipnotlar ve Son Notlar}

Çalışmanın bu kısmında yukarıda genel hatlarıyla anlatılan Hocalı Soykırımı ile ilgili olarak farklı toplum kesimlerin temel tutumları ve görüşlerini analiz eden araştırmanın amacı, evren ve örneklemi, yöntemi ve bulguları sunulmaktadır. Araştırma 15 Şubat 2018 tarihinde başlayıp 15 Mart 2018 tarihinde sonlandırılmıştır.

\subsection{Araştırmanın Amacı}

Hocalı Soykırımına yönelik farklı toplum kesimlerinin tutumlarını ve düşüncelerini ortaya koymaktır. Bu amaç doğrultusunda özellikle Azerbaycan Devleti'ne Hocalı Soykırımı ile ilgili kamuoyu oluşturma sürecine yönelik bilgiler sunulacaktır.

\subsection{Araştırmanın Evreni ve Örneklemi}

Evren araştırmacının sosyal medya hesaplarında araştırmacıyı takip eden takipçilerden oluşmuştur. Kolayda Örnekleme yöntemiyle araştırmacının kendi sosyal medya hesaplarında yer alan farklı toplum kesimlerinden takipçilerine Yapılandırılmış Soru Formu gönderilmiştir. Soru Formunu cevaplamayı kabul eden ve dönüş yapan 198 kişi olmuştur.

\footnotetext{
${ }^{1}$ Sarkisyan'ın uluslararası hukuku, insani değerleri yok sayan söylemleri bununla da sınırlı değildir. Sarkisyan 17 Mayıs 2001'de yaptı̆̆ı başka bir açıklamada, "İşgal ettiğimiz topraklar var. Bunda utanılacak bir şey yok. Güvenliğimiz gereği yaptık. Biz bunu 1992'de de söylüyorduk, şimdi de söylüyoruz" şeklinde ifadeler kullanırken, cumhurbaşkanı sıfatıyla 2011'de üniversite öğrencilerine yaptığı bir başka konuşmada "Karabağ’ı bizim neslimiz aldı, Ağrı'yı da size bırakıyoruz" sözlerini kullanabilmiştir. Bu durum Ermenistan'ın mütecaviz eylem ve söylemlerinin adeta bir devlet politikası haline geldiğinin de kanıtıdır. Bu haliyle Ermenistan, üyesi olduğu Birleşmiş Milletler ve AGIT'in en temel normları sayılan "sınırların değişmezliği" ve "ülkelerin toprak bütünlüklerine saygı" ilkelerini de açıkça ihlal emektedir.
} 


\subsection{Araştırmanın Yöntemi}

Araştırmada veri toplama yöntemi olarak Yapılandırılmış Mülakat kullanılmıştır. Bilindiği üzere mülakat yöntemi hem nicel hem de nitel araştırmalarda kullanılmaktadır. Yapılandırılmış mülakat yönteminde önceden hazırlanmış sorular görüşmecilere iletilmekte ve verdikleri cevaplar kayıt altına alınmaktadır (Arslan ve Özen, 2018: 129). Araştırmanın konusu doğrultusunda önceden hazırlanmış olan 7 adet soru görüşmeyi kabul eden kişilere yöneltilmiştir. Bu görüşmeler neticesinde elde edilen veriler birincil verilerdir çünkü doğrudan kişilere Hocalı Soykırımı ile ilgili görüşleri sorulmuştur.

Yapılandırılmış görüşmeler neticesinde elde edilen metinler üzerinde İçerik Analizi gerçekleştirilmiştir. İçerik analizinde bir dizi usul kullanılarak görüşmeler neticesinde elde edilen metinlerden sonuçlar çıkarılmıştır (Weber, 1990: 9). Metinler içerisinde bazı temalara (konulara) yani birtakım kelimelere veya kelime anlamlarına odaklanarak kodlama yapılıp, bu kodlamalar neticesinde; Temasal Analiz, Semantik Analiz veya Ăg Analizi olmak üzere üç çeşit içerik analizinden biri kullanılabilir (Leblebici ve Kılıç, t.y: 7). Bu araştırmanın verilerinin analiz etmede kullanılan Temasal Analiz, el yordamıyla yapılabildiği gibi, metinler Paket Programlara (örneğin NVivo) yüklenerek kelimeleri keşfetmek, frekans dağılımlarını görmek ve kavram haritalarını çıkarmak şeklinde de yapılabilmektedir. Sorularda yer alan ve ima edilen kavramlar ve kategoriler gözlemlenir ve gözlemlenen ilişkiler sayesinde yorumlara gidilebilmektedir (Bazeley ve Jackson, 2013:249). Bu çalışmada NVivo 12 Paket Programı yardımıyla İçerik Analizi (Temasal Analiz) yapılmıştır. Elde edilen frekans dağılımları ve kavram haritaları sayesinde yorumlara gidilmiştir.

\subsection{Araştırmanın Bulguları}

Araştırmaya katılmayı kabul edenlerin 94 (\%47,5)'ü kadın, 104 (\%55,5)'ü erkektir. Katılanlardan; 47 (\%23,7)'si üniversite öğrencisi, 32 (\%16,1) akademisyen, 37 (\%18,6)'si devlet memuru, $28(\% 14,10)$ 'i işçi, 54 (\%27,20)'ü serbest meslek erbabı durumundadır. $78(\% 39,30)^{\prime} i$ Ortaöğretim mezunu, 65 (\%32,80)'si Lisans mezunu ve $55(\% 27,7)$ 'i Lisansüstü eğitim düzeyine sahip olduğunu beyan etmiştir.

Araştırmaya katılanların yapılandırılmış mülakatta kendilerine iletilen 7 soru ile ilgili olarak verdikleri cevaplardan oluşan metinlere paket program vasıtasıyla Temasal Analiz gerçekleştirilmiştir. Öncelikle oluşan metinlerde aynı anlama gelen birbirine benzeyen ve bir grup altında toplanabilecek olan kelimeler aynı kelime veya kelime grubu içerisinde toplanmıştır. Bu kelime ya da kelime gruplarının frekans dağılımları ve kavram haritaları her bir soru için aşağıdaki gibi ortaya çıkmıştır:

\section{Soru 1.: Size göre Hocalı'da yaşanan olaylar nasıl tanımlanmalıdır?}

Araştırmaya katılanların bu soruya verdikleri cevaplardan oluşan metinler de yaşanan olayı tanımlamayla ilgili kelime ve kelime grupları 82 kez tekrarlanmıştır. Bu kelime ve kelime gruplarının frekans ve yüzdeleri şöyledir: Soykırım 42 (\%51,21), Katliam $24(\% 29,26)$, Vahşet $9(\% 10,97)$, İnsanlık Suçu $6(\% 7,31)$, Etnik Temizlik $3(\% 3,65)$. Katılımcıların 198 kişi olmasına rağmen metinler içerisinde Hocalı Soykırımı ile ilgili sadece 82 kez tam bir kavramsallaştırma olması ilginç bir sonuçtur. 
Şekil 1. Hocalı'da Yaşananların Tanımlanmasıyla İlgili Kavram Haritası

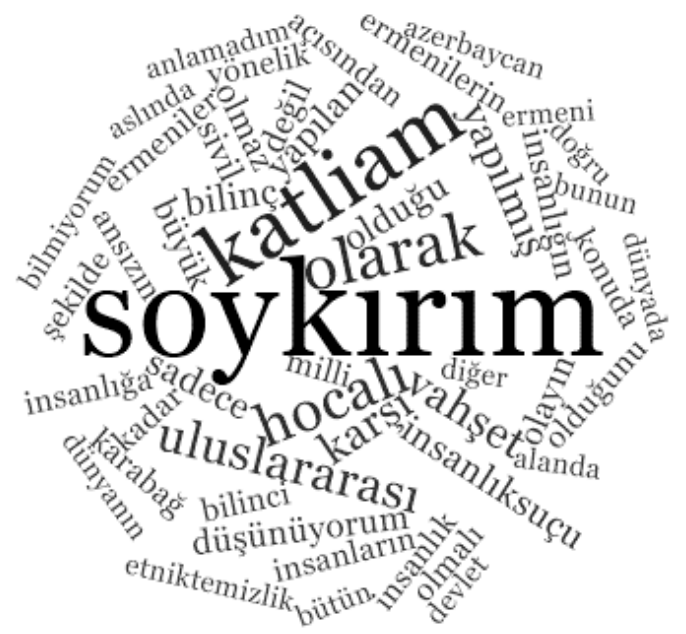

\section{Soru 2.: Hocalı Soykırımı'ndan ilk kez ne zaman haberdar oldunuz?}

Verilen cevaplar itibariyle belirli bir zaman süreci ifade edebilecek kelime ve kelime grupları açısından toplam 195 frekans oluşmuştur yani, bu kelime ya da kelime grupları 195 kez tekrarlanmıştır. Bu kelime ve kelime grupları ve tekrarlanma sayıları ve yüzdeleri şöyledir:

2000 y1lı sonras1 $77(\% 39,48), 1992-2000$ aras1 42 (\%22,05), Ortaöğretim 24 (\%12,30), Çocukluk ve ailede 23 (\%11,79), Üniversite $14(7,17)$, İlkokul $9(\% 4,61)$ ve yeni duyanlar $5(\% 2,56)$. Şekil 1.'deki kavram haritasına bakıldığında soykırım yılı olan 1992'nin ağırlık kazandığı görülmekle birlikte esasen 2000'li yıllardan sonra haberdar olanların sayısı fazladır. Bunun temel nedenlerinden birinin katılımcılar içerisinde gençlerin sayıca fazla olması olduğu gibi 2000'li yıllardan sonra Azerbaycan Devleti’nin Hocalı Soykırımı ile ilgili kamuoyu oluşturma çalışmalarına daha fazla yoğunlaşması olabilir.

Şekil 2. Hocalı Soykırımından Ne Zaman Haberdar Olunduğu İle İlgili Kavram Haritası

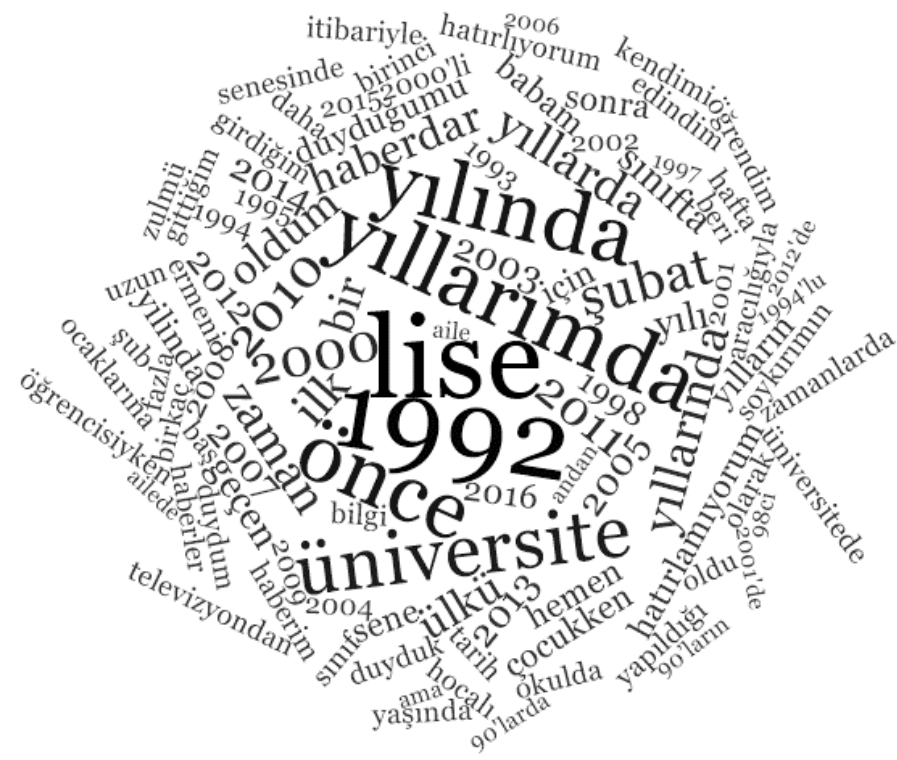


Soru 3.: Hocalı soykırımına ilişkin farkındalığınız hangi olaylar ve deneyimler sayesinde oluştu?

Araştırmaya katılanların bu soruya verdikleri cevaplardan oluşan metinler de Hocalı soykırımıyla ilgili farkındalı̆̆ olanların bu farkındalıklarının oluşumunda etkili olabilecek unsurlarla ilgili kelime ve kelime grupları 152 kez tekrarlanmıştır. Bu kelime ve kelime grupları ve tekrarlanma sayıları ve yüzdeleri şöyledir:

Konferans 23 (\%15,13), TV 21 (13,81), Öğretmenler 16 (\%10,52), Üniversite $16(\% 10,52)$, Sosyal Medya 14 (\%9,21), Ülkü Ocakları 11 (\%7,23), Kitap 10 (\%6,57), Bireysel Araştırma $9(\% 5,92)$, İnternet $8(\% 5,26)$, Tanıkları İzleme $8(\% 5,26)$, Arkadaştan Duyma $5(\% 3,28)$, Gazete $4(\% 2,63)$ ve Dergi $3(\% 1,97)$.

Şekil 3. Hocalı Soykırımıyla İlgili Farkındalığın Nasıl Oluştuğu İle İlgili Kavram Haritası

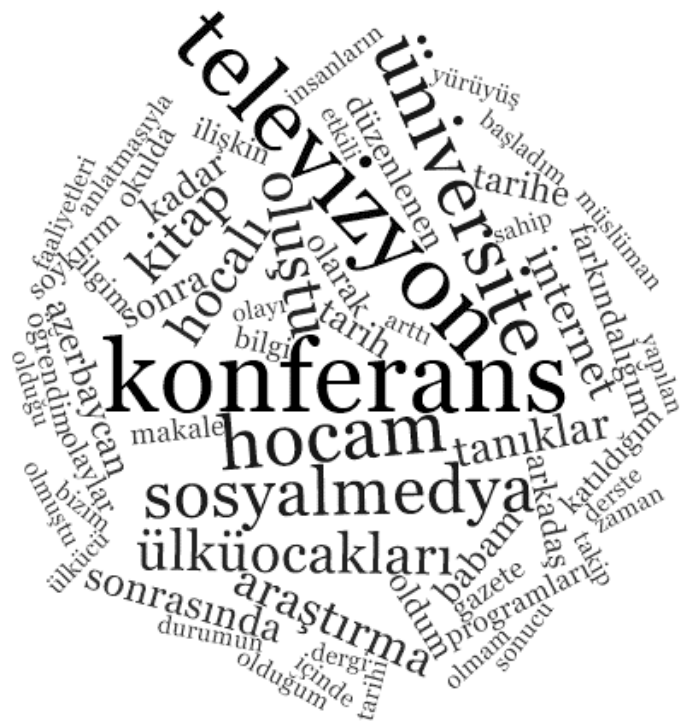

Soru 4.: Hocalı Soykırımı'nın uluslararası alanda yeterince tanıtıldığına inanıyor musunuz?

Görüş̧e formunu dolduran katılımcıların dördüncü soru ile ilgili cevaplarından oluşan metinlerde Hocalı Soykırımının uluslararası alanda yeterince tanıtıldığına dair düşüncelerini ortaya koyabilecekleri kelime veya kelime grupları $221 \mathrm{kez}$ tekrarlanmıştır. İlgili kelime ve kelime grupları ve tekrarlanma sayıları ve yüzdeleri şöyledir:

Hayır $163(\% 73,7)$, İnanmıyorum $34(\% 15,38)$, Yeterli Değil $7(\% 3,16)$, Maalesef $6(\% 2,26)$, Yeterli $(\% 2,26)$, Düşünmüyorum $5(\% 2,26)$. Metinlerde tekrar okunduğunda katılımcıların neredeyse tamamının etkili bir uluslararası tanıtımın yapılamadığı konusunda hem fikir olduğu görülmektedir. Diğer taraftan yeterince tanıtılmaktadır diyen katılımcılar da tanıtımın etkili olmamasını ya dünyanın diğer millet ve devletlerinin önemsememesine ya da Ermeni Diasporasının etkinliğine bağladığı görülmektedir. 
Şekil 4. Hocalı Soykırımı'nın Uluslararası Alanda Yeterince Tanıtılma Durumuna İnanma Kavram

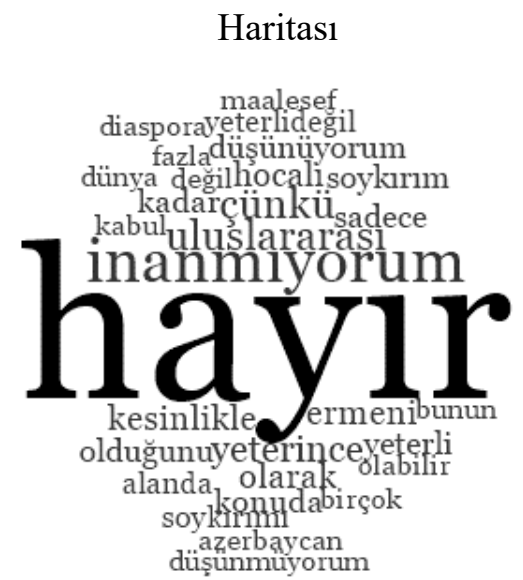

Soru 5.: Sizce Türkiye ve Azerbaycan Hocalı Soykırımı'nı tanıtmak için yeterince lobi faaliyeti yapıyorlar mı?

Hocalı Soykırımı ile ilgili Türkiye ve Azerbaycan'ın Lobi faaliyetlerinin yeterli olup olmadığı ile ilgili kelime veya kelime grupları $221 \mathrm{kez}$ tekrarlanmıştır. İlgili kelime ve kelime grupları ve tekrarlanma sayıları ve yüzdeleri şöyledir:

Hayır $110(\% 67,48)$, Kısmen $35(\% 17,24)$, Evet $13(\% 6,40)$, Yeterli $13(\% 6,40)$ ve Bilgim Yok $4(\% 1,97)$. Katılımcıların çoğunluğu lobi faaliyetlerinin yeterli olduğunu düşünmüyor. Yeterli olduğunu düşünen katılımcılarda genellikle diğer ülkelerin görmezden geldiğini veya Ermeni Diasporasının güçlü ve daha etkili olduğunu dolayısıyla Türkiye ve Azerbaycan'ın lobi faaliyetlerinin etkisizleştiğini düşünüyorlar.

Şekil 5. Azerbaycan ve Türkiye'nin Hocalı Soykırımı İle İlgili Lobi Faaliyetleri Yapma Durumuyla İlgili Kavram Haritas 1

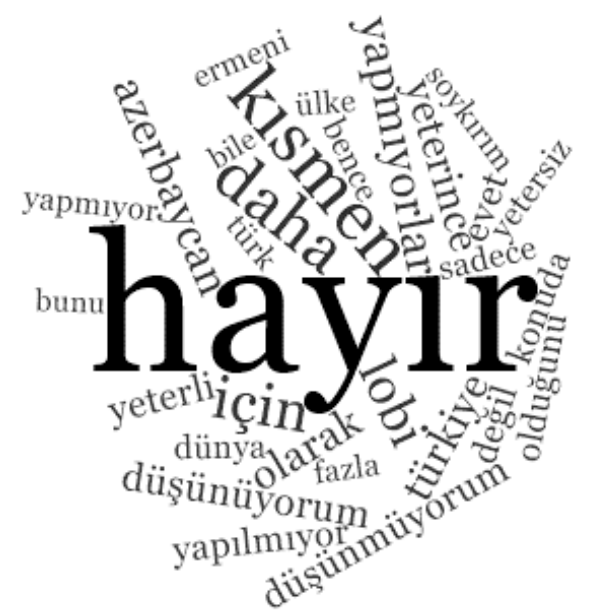

Soru 6.: Hocalı Soykırımı'ndan haberdar olduktan sonra bu olayı uluslararası alanda duyurmak için bireysel veya grup olarak herhangi bir çalışma yaptınız mı?

Hocalı Soykırımı ile ilgili katılımcıların bireysel veya grup olarak yapmış oldukları faaliyetler ile ilgili kelime veya kelime grupları $221 \mathrm{kez}$ tekrarlanmıştır. İlgili kelime ve kelime grupları ve tekrarlanma sayıları ve yüzdeleri şöyledir: 
Hayır $97(\% 48,01)$, Evet $43(\% 21,28)$, Sosyal Medya 33 (\%16,33), Bireysel $8(\% 3,96)$, Üniversite $8(\% 3,96)$, Konferans $7(\% 3,46)$ ve Uluslararası $6(\% 2,97)$. Ortaya çıkan frekans ve yüzde dağılımları katılımcıların yarıya yakınının Hocalı Soykırımı ile ilgili bir faaliyette bulunmadığını göstermektedir. Gerçekleştirilen faaliyetlerle ilgili olarak da en çok yapılanın sosyal medya paylaşımları olduğu dikkati çekmektedir. Bu faaliyetlerde ise uluslararası düzey sayısı çok az görünmektedir.

Şekil 6. Hocalı Soykırımı İçin Bireysel ve Grup Olarak Yapılan Faaliyetlerle İlgili Kavram Haritası

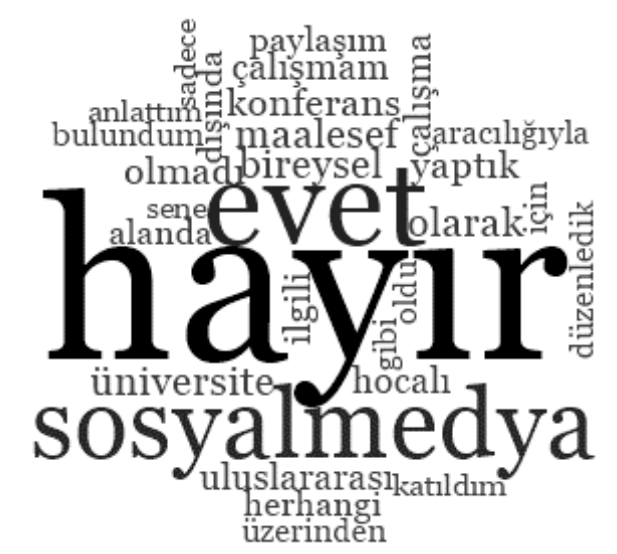

Soru 7.: Hocalı Soykırımına farkındalığı arttırmak için toplumsal ve kurumsal düzeyde ne yapılmalıdır?

Hocalı Soykırımı ile ilgili olarak esasen millet ve devlet olarak neler yapılmasının farkındalığı artırabileceği ile ilgili sorulan bu soruya verilen cevaplarla oluşan metinler üzerinde gerçekleştirilen analiz neticesinde ilgili kelime veya kelime grupları 199 kez tekarlanmıştır. İlgili kelime ve kelime grupları ve tekrarlanma sayıları ve yüzdeleri şöyledir:

Uluslararas1 Faaliyetler 38 (\%19,08), Sosyal Medya $26(\% 13,06)$, Konferanslar $26(\% 13,06)$, Medya 19 (\%9,54), Üniversiteler 14 (\%7,03), Lobicilik 12 (\%6,03), Belgesel 11 (\%5,52), Anma Programları $9(\% 4,52)$, Gündem 9 (\%4,52), Okullar 8 (\%4,02), Bilimsel Çalışma $6(\% 3,01)$, Kamuoyu $6(\% 3,01)$, Filmler $5(\% 2,51)$, Kitap $5(\% 2,51)$ ve Seminerler $5(\% 2,51)$. Görüldüğü üzere kamuoyu oluşturmanın yolları söylenmekle birlikte bu faaliyetlerin uluslararası düzeyde gerçekleştirilmesi gerekliliği daha fazla vurgulanmış durumdadır. 
Şekil 7. Hocalı Soykırımı İle İlgili Farkındalığın Nasıl Artırılabileceği Düşünceleri İle İlgili Kavram

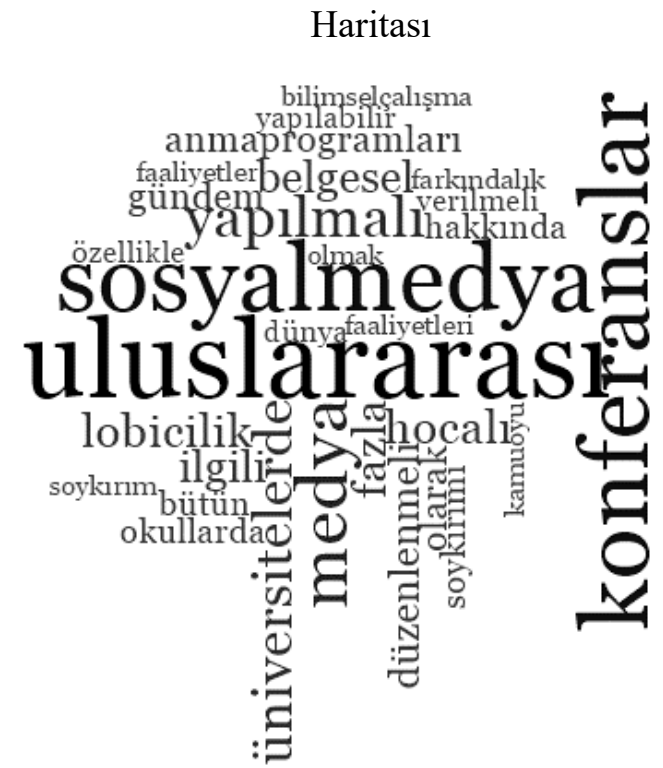

\section{SONUÇ VE DEĞERLENDİRMELER}

İçerik Analizi sonucunda, örneklem dâhilinde kamuoyunda Hocalı Soykırımı ile ilgili olarak bazı algılar ve tutumlar tespit edilmiştir. Bu çerçevede öncelikle katılımcıların önemli bir kısmının Hocalı Soykırımı konusunda oldukça hassas oldukları söylenebilir. Bununla birlikte, genel bilgiler dışında Hocalı'da yaşananların temel nedenleri hakkında bilgi düzeyinin oldukça sınırlı olduğunu söylemek de mümkündür. Hocalı faciasının uluslararası topluma duyurulması noktasında toplumsal bilincin oldukça düşük seviyelerde olduğu, konunun genel olarak olaya vakıf mecralarda dile getirildiği, uluslararası kamuoyuna bu soykırımın duyurulması noktasında çok fazla girişimde bulunulmadığ 1 da çalışma kapsamında tespit edilmiştir. Ancak sayıca oldukça az olmakla birlikte, bazı katılımcıların sosyal medya aracılığıyla konuyu uluslararası alanda tanıtmak için uğraştıklarını söylemek de mümkündür. Katılımcıların yarısından fazlasının (\%51) Hocalı'da yaşananları soykırım olarak değerlendirmesi, örneklem bazında da olsa olaya yönelik bir "soykırım" algısının toplumda yerleşmeye başladığını göstermektedir.

Sosyal medya kanallarının gelişmesi ve kullanıcı sayılarının artmasının ile Hocalı soykırımı daha fazla kişi tarafından bilinir hale gelmiştir. Olayın duyulmasında özellikle yapılan etkinliklerin ve medyanın oldukça etkili olduğu da ortaya çıkan sonuçlar arasındadır. Hocalı ile ilgili farkındalığın özellikle lise ve üniversite yıllarında arttığı, bu noktada eğitim sürecinde düzenlenen toplantıların oldukça etkili olduğu, öğrenci kulüplerinin ve bazı sivil toplum kuruluşlarının (Ülkü Ocakları vb.) da Hocalı'da yaşananların kamuoyu tarafından duyulmasında önemli bir işlev gördüğü saptanmıştır. Konu hakkında özellikle eğitim kurumlarında öğrencilerin bilinçlendirilmesi gerektiği, hatta yaş aralığına uygun olarak çok daha erken dönemlerde; okuma parçaları, okul panoları, şarkılar gibi araçlarla çocuklara olayın anlatılması gerektiği yönünde de görüşler mevcuttur. Mülakat yapılan katılımcılar arasında sinema, dizi, belgesel ve tiyatro gibi etkinlikler aracılığıyla konunun dile getirilmesi gerektiğini 
vurgulayanların oranı da hayli yüksektir. Bununla birlikte, farklı dillerde yayınlar yapılarak dünya kamuoyunun Hocalı'da yaşananlar hakkında bilgilendirilmesinin gerektiği de birçok katılımcı tarafından dile getirilmiştir.

Herhangi bir konuda "kamuoyu" oluşturulmasında süreklilik, istikrar ve tekrarın ne denli önemli olduğundan hareketle, konu ile ilgili faaliyetlerin tüm yılı kapsaması gerektiği, uluslararası toplumun dikkatini çekmenin ancak bu şekilde mümkün olabileceği, sadece Şubat ayı yaklaşırken konunun gündeme gelmesinin yeterli olmadığı da önemli sayıda katılımcı tarafından belirtilmiştir. Konunun uluslararası hukuk çerçevesinde ele alınması gerektiği, bu çerçevede özellikle olayın faillerinin günümüze kadar herhangi bir müeyyide ile karşılaşmamasının Türkiye ve Azerbaycan tarafından daha yüksek sesle dile getirilmesi gerektiği de katılımcıların vurguladığı konular arasındadır. Kanımızda bu vurgu, Hocalı'da yaşananların sadece Türk dünyasını değil tüm insanlığı ilgilendirdiği, böylesi bir sivil katliamın göz ardı edilmesinin dünyanın farklı bölgelerinde bu tür gayriinsani girişimlerde bulunmak isteyenleri teşvik edeceği gerçeği de dikkate alınarak yapılırsa, dünya kamuoyunun dikkatini çekmek kolaylaşabilir. Çünkü uluslararası hukuk açısından en büyük insanlık suçu olarak kabul edilen soykırımı gerçekleştirenlerin cezasız kalması etnik, dini ve kültürel birçok çatışmanın yaşandığı günümüzde bu tür yeni faciaların yaşanma olasılığını artırabilir.

Bununla birlikte olayın faillerinin cezalandırmak bir yana, neredeyse ödüllendirilmeleri de Hocalı Soykırımı'nı daha da hassas bir noktaya getirmektedir. İnsan Hakları İzleme Örgütü'nün, Dağlık Karabağ Savaşı'ndan bu yana gerçekleştirilen en kapsamlı "sivil" katliam olarak nitelendirdiği bu facianın yaşandığı dönemde Dağlık Karabağ'da Ermeni güçlerine komutanlık eden Serj Sarkisyan 20082019 yılları arasında Ermenistan Cumhurbaşkanlığı yapmış ve tüm dünyada "kırmızı bültenle" aranması gerekirken tabiri caizse "kırmızı halılarla" karşılanmıştır. Bu durumun özellikle dünyada çatışmaların yoğun olarak yaşandığı bölgelerdeki taraflara verdiği mesaj oldukça tehlikelidir: Herhangi bir ülkenin toprağını işgal edebilirsiniz, BM Güvenlik Konseyi'nin aldığg kararlara rağmen bu mütecaviz tutumunuzu devam ettirebilirsiniz, hatta işgal ettiğiniz yerlerdeki insanları "soykırıma" tabi tutabilirsiniz, bu soykırımın baş failleri üst düzey devlet görevlisi olabilir ve tüm dünya liderleri ile hiçbir sıkıntı yaşamadan ilişki kurabilir. Bu bakımdan Hocalı Soykırımı ve benzeri hadiseler, sadece olayın yaşandığı bölge barışını değil, tüm dünya barışını da etkilediği için uluslararası toplumun bu tür hadiselere daha duyarlı olması beklenmektedir.

Katılımcıların önemli bir kısmı Hocalı Soykırımı'nın uluslararası alanda yeterince tanıtılamadığı ve Türkiye ve Azerbaycan'ın bu konuda gerektiği kadar lobi faaliyeti yapamadığı algısına sahiplerdir. Olaya ait farkındalığın artırılması için etkinliklerin, konferansların, anma programlarının daha fazla yapılması ve sosyal medyanın özellikle uluslararası düzeyde daha etkin kullanılması yönünde bir kanının ortaya çıktığı da tespit edilmiştir. Dolayısıyla Azerbaycan ve Türkiye'nin Hocalı Soykırımı ile ilgili lobi faaliyetinin yeterli olmadığını düşünenler sayıca ağırlıklıdır. Ortak lobi çalışmalarını yeterli gören katılımcıların cevapları neticesinde oluşan metinler ayrıntılı olarak okunduğunda ise, Batı dünyasının olayı görmezden gelmesi ve Ermenistan diasporasının ekonomik ve siyasi gücü nedeniyle 
yapılan çalışmaların gölgede kaldığı yönünde de bir algının oluştuğu görülmüştür. Hatta bazı katılımcılar, lobicilik faaliyetleri için boşuna zaman harcanmaması gerektiğini, bu olayın -etnik ve dini nedenlerden dolayı- Batı'nın dikkatini çekmediğini, bu durumun da bu soykırımın uluslararası düzeyde tanıtılmasını oldukça zorlaştırdığına inanmaktadırlar. Hocalı Soykırımı'nın tanıtılmasında yalnızda devletlerarası resmi düzeyde yapılan girişimlerin yeterli olmadığ 1 , hatta bundan daha da önemli olanın uluslararası düzeyde kamu diplomasisinin daha etkin kullanılması olduğu yönünde de bir saptama yapılmıştır.

Katılımcıların büyük bir çoğunluğunun Hocalı soykırımını özellikle 2000'li yıllardan sonra öğrendikleri görülmüş̧ür. Bu durum katılımcılar içerisinde gençlerin sayıca fazla olması ile ilgili olduğu kadar, son yıllarda sosyal medya ağlarının gelişmesiyle de alakalıdır. Azerbaycan Devleti'nin 2000'li yıllardan sonra Hocalı Soykırımı ile ilgili uluslararası düzeyde kamuoyu oluşturma çalışmalarına daha fazla yoğunlaşmasının, bu olayın daha fazla duyulmasına katkı sağladığı yorumu da yapılabilir. Son yıllarda sahip olduğu enerji gücünü dış politikada daha etkin bir baskı aracı olarak kullanan Azerbaycan, özellikle Dağlık Karabağ sorununun çözümünde uluslararası destek alabilmek için "enerji diplomasi"sini ciddi anlamda kullanmaktadır. Haydar Aliyev'in; "Petrol yalnızca bir meta değil, Azerbaycan için özgürlüktür" sözleri ile özetlenebilecek bu politika, Hocalı Soykırımı'nın uluslararası alanda daha fazla duyurulmasına büyük katkı sağlamaktadır. İlham Aliyev'in hemen hemen katıldığı her toplantıda konuyu gündeme getirmesi de bu politikanın bir yansımasıdır.

\section{KAYNAKLAR}

ALKAN, A. (2006), Karadeniz Güvenliği, Ankara: Nobel Yayınları.

ARSLAN, Ş., ÖZEN, M. (2018), Nicel Araştırmada Veri Toplama Yöntemleri ve Veri Türleri, Arslan, Ş. İçinde, Sosyal Bilimlerde Araştırma Yöntemleri, Konya: Eğitim Yayınevi.

ASKER, A. (2017), "Hocalı Soykırımı", 21. Yüzyll Türkiye Enstitüsü, http://www.21yyte.org/tr/arastirma/azerbaycan/2012/02/24/6106/hocalisoykirimi\#_ftn ref5, adresinden alındı. Erişim tarihi: 10.05.2017.

ASLANLI, A. (2001), Tarihten Günümüze Karabağ Sorunu, Avrasya Dosyası, Cilt 7, Say1 1, ss. 593-430.

ATABEK, N. (2002), Kamuoyu, Medya ve Demokrasi, Kurgu Dergisi, Say1 19, ss. 223-238.

ATTAR, A. (2013), 1830-1930 Yılları Arasında Çeşitli Nedenlerden Türkiye’ye Göç Etmiş Azerbaycan Türkleri, Attar, A. ve Şimşir, S. içinde, Tarihten Günümüze Türkiye'de Yaşayan Azerbaycan Türkleri, Ankara: Berikan Yayınevi.

BAGIROV, F. (2017), Hocalı Soykırımı'nın 25. Yı1 Dönümü, http://ankara.mfa.gov.az/files/file/Hocali_Soykirminin_25._Yildonumu.pdf adresinden alındı. Erişim tarihi: 01.05.2017. 
BAZELEY, P. JACKSON, C. (2013), Qualitative Data Analysis With NVIVO, Second Edition, Los Angeles: SAGE Publications.

BUNIYATOV, Z. M. (1991), “Azerbaycan”, İslam Ansiklopedisi, Türkiye Diyanet Vakfı Yayınlar1, Cilt 4, ss. 322-324.

DUGIN, A. (2005), Rus Jeopolitiği, Çev. Vügar İmanov, İstanbul: Küre Yayınları.

KAPANI, M. (1983), Politika Bilimine Giriş, Üçüncü Baskı. Ankara: Ankara Üniversitesi Yayınlar1.

LEBLEBİCI D. N. KILIÇ, M. (2004) İçerik Analizi, Ankara: Hacettepe Üniversitesi İ.İ.B.F. Yayınları.

MEHMETOV, İ. (2009), Türk Kafkası'nda Siyasi ve Etnik Yapı, İstanbul: Ötüken.

ÖZDAŞLI, E. (2015), Son Türk Soykırımı: Hocalı, Dergi Ayrıntı, Cilt 3, Sayı 24, ss. 12-17.

ÖZDAŞLI, E. KODAMAN, T. (2016), Stratejik Ortaklık Kavramı Bağlamında İsrail Azerbaycan Illişkileri, Ankara: Orion.

WEBER, P. W. (1990), Basic Content Analysis, 2nd Edition, California: Sage Publications.

YEŞILIOT, O. (2008), Türkmençay Anlaşması ve Sonuçları, A.Ü. Türkiyat Araştırmaları Enstitüsü Dergisi, Sayı 36.

YÜKSEL, E. (2007), Kamuoyu Oluşturma" ve "Gündem Belirleme" Kavramları Nerede Kesişmekte, Nerede Ayrılmaktadır?, Anadolu Üniversitesi Sosyal Bilimler Dergisi, Cilt 7, Say1 1, ss. 571-586. 